CHAPTER 11

\title{
The Necropolis of an Early Makurian Elite
}

\author{
Mahmoud El-Tayeb and Ewa Czyżewska-Zalewska
}

To contextualise the necropolis at El-Zuma in the history of Ancient Nubia and demonstrate its elite status within local social structures, we need to look at it from various perspectives: from the purely architectural aspect of the grave constructions, as well as from cultural and religious angles. We also need to take into account the specific period to which this cemetery is attributed, between the fall of the Royal Authority of the Meroitic kingdom and the rise of Makuria as an independent political entity, when changes in political systems were often not synonymous with the usually slower and more gradual changes that took place in everyday culture and religious practices. No doubt, regionalism and ethnic societal composition are amongst the significant factors that had an effect (positive or negative) on the changes that took place during the later phase of the Meroitic kingdom. These aspects of change and evolution, scrupulously observed and analysed during the excavations, enabled us to situate El-Zuma cemetery in Nubian history, and to determine the status of the burial occupants in the local society. Hence, as mentioned in the introduction, these three volumes aim to showcase the results obtained from studying the archaeological evidence. First of all, what we have learned about burial construction and its development; then, mortuary practice and grave furnishings. This is followed by studies of pottery vessels, personal adornment, and armaments as essential cultural items of each historical period.

Evolution and gradual changes are evident in the construction of the tombs at El-Zuma: from the simple structures of type II tombs, which are deeply rooted in classic Meroitic traditions, followed by the emergence of a new type of grave with a rectangular shaft and lateral niche, ending with a U-shaped shaft with double, or multi, side chambers.

Prior to the Fourth Nile Cataract salvage campaign, which was conducted in the years 1996-2010, archaeologists had paid little attention to the study of Meroitic funerary customs and their development in the Dongola Reach. The results of excavations in various districts within the Reach revealed that the earliest known type of Meroitic burials had followed the Pharaonic tradition, which had been adopted by the Kushites of the Twentyfifth Dynasty during the Napatan period (850-590 BC). Francis Griffith noted that the simple common burial con- sisted of a pit aligned north-south, in which the body was laid in a supine position, hands on the pelvis area, with the head due north (Griffith 1923). Later developments show some signs of a revival of indigenous mortuary traditions in different forms. The best known of these forms are burials with a long or short descendary, terminating in a niche cut into its west side. This type of sloping ramp was known in the Dongola Reach as early as the Napatan period, where it was first constructed beneath the Royal pyramids at El-Kurru (Dunham 1950). Thereafter, a more modest version was adopted in the graves of commoners during the Napatan and Classic Meroitic periods (Lenoble 1987; Welsby 2018). Burials featuring lateral niches appeared during the Classic Meroitic period (1st century BC-2nd century AD) and continued to be constructed until the last phase of Meroitic culture (AD 450-6oo). The beehive type of burial that originated in the Gezira region south of Khartoum is also noted in the Dongola Reach. The rectangular shaft, oriented east-west, provided at the bottom with a side chamber hewn into the southern wall of the shaft, was dominant in the Reach during the first phase of the Terminal Meroitic period ( $A D$ 350-45 $)$. A revival of indigenous traditions can be seen not only in tomb construction but also in the way that bodies were buried. The deceased was usually laid in a contracted position, often in east-west or north-south alignment. A later development in this type of grave, that to date has only been noted in the Dongola Reach, is the U-shaped shaft characterised by a pier projecting from the east wall of the shaft. In some cases these graves were provided with an underground tunnel aligned south-north, terminating at the main burial chamber. In this last phase (AD 450-60o), the main burial chamber was always cut into the southern wall of the shaft, while the body was placed at the east end of the main burial chamber, in a contracted position, head to the east, facing north (for more information, see Edwards 1991; Mahmoud El-Tayeb 2002; 2012, 9, 41-84; Kołosowska and Mahmoud El-Tayeb 2007, 11-25).

Among the 29 burials excavated at El-Zuma, only eight have underground tunnels, attesting to the dead individual's high standing in local society. Furthermore, the variety in tunnel construction, from simple tunnels (T.2, T.3, T.5, T.8) to more sophisticated ones that are wider and supported by solid pillars hewn from the same bed- 
rock (T.1, T.4, T.6, T.7), is not only a sign of the elevated rank of those buried in these graves, but evidently of their elite status too, though we cannot say that they were "royalty" without further evidence to confirm this supposition (Mahmoud El-Tayeb 2012, 9, 41-84).

Looking at the grave goods buried with the deceased, it is difficult to ignore the aspect of religion and a certain symbolism. The deposition of food offerings, bearing traces of consumption, was a well-known tradition among ancient Nubian societies from the Mesolithic period until the conversion to Christianity. It is a tradition that attests to the awareness of the Nubians and their deep and longlasting belief in eternity and the afterlife. The presence of cooking pots and large bowls normally used in food preparation may also have served as a sort of symbolic affirmation of everyday earthly life (see Chapter 8 , this volume and Volume II, Chapter 4).

In the case of mortuary rites, one question that remains unresolved is whether or not the pottery found outside burial chambers (e.g., in shafts) was associated with funerary rites, interpreted by Lenoble as a "funerary banquet." This practice was noted in earlier periods (Lenoble 1994). Examples of processing marks noted by Urszula Iwaszczuk on animal bones found in El-Zuma grave shafts alongside pottery, may point to this (see Chapter 8 , this volume); however, the fact that these graves were looted means that this theory cannot be confirmed conclusively, as the pottery may also have been displaced during the ransacking of the burial chambers.

Social stratification is also apparent at the El-Zuma necropolis. The differentiation of the graves into three types, which probably reflect the grave occupant's status in the local social hierarchy, is manifest not only in the structure of the tombs but also in the grave goods and furnishings. Although all three types of graves had suffered various degrees of looting, nevertheless, a range of personal adornments, including jewellery that is attributed to the elite class, such as that noted at Ballana and Qustul, was found primarily in type I graves, whereas examples of jewellery recovered from graves of types II and III were far less opulent (see Volume III, Chapters 2-5). This distinction is also noticeable in the food offerings. Better and more varied types of meat were found in type I graves, while the other two grave types contained fewer varieties and smaller quantities of meat (see Volume II, Chapter 8). This cannot be taken as definite evidence of social differentiation due to the heavily plundered state of the burials; however, pottery, which was usually the main component of the grave goods, offers some further clues. More significant numbers and greater varieties of vessels were found in type I tumuli, which also featured imported pottery. Although type II tumuli sometimes contained significant quantities of ceramics, the types of vessels were far less diverse, and imports were noted only sporadically. The sets of pottery found in type III tumuli were very modest, comprising several vessels of two or three types. The geographical location of the Dongola Reach, as a middle zone between Lower Nubia and the Shendi Reach [see Fig. 11.1], explains the presence of handmade vessels, such as the large beer jars imported from the south, while more sophisticated, small, wheel-made vessels were mainly local products or northern imports from Lower Nubia (see also Volume II, Chapter 6, Figs. 6.2, 6.4, 6.10). Based on the grave architecture and burial goods, we can conclude that the largest tombs were the most elite, whilst the smallest ones were the graves of individuals ranked lower in the social hierarchy.

It is worth drawing attention to the weaponry found in some of these graves. Łukasz Zieliński's analysis shows that arrowheads predominate in this assemblage, but it also includes javelins, knives, and archer's thumb rings, which were found mostly in graves of types II and III, accompanying males aged 30-45 years. We can assume that they were probably meant to denote the social status of these individuals, who may have been warriors or hunters, or even dignitaries who ran elite workshops producing pottery, iron weapons, adornments, bronze work, and a variety of tools. Most of the weapons show traces of use, whilst most of the thumb rings were clearly not used (see Volume III, Chapter 14). Based on grave architecture, we can conclude that hunters/warriors and other dignitaries occupied a lower position in the social hierarchy, as most of them were buried in tumuli of types II and III.

The most important question to address is the chronology of this site. Where does El-Zuma fit within the history of Ancient Nubia, and where is its position on the timescale of other important sites of this period such as Ballana, Qustul, El Hobagi, and Tanqasi?

Analysis of personal adornments by Joanna ThenObłuska and weaponry by Łukasz Zieliński places ElZuma at the end of the Meroitic period, as both sets of finds show that Meroitic culture endured at this site till the conversion to Christianity in the mid-6th century AD. Ewa Czyżewska-Zalewska's analysis of the pottery also shows that Meroitic traditions continued and gradually evolved over time, with new vessel forms (e.g., Dongolan amphorae) associated with the Christian Kingdom of Makuria and its capital at Dongola later appearing in some graves. The repertoire of vessel forms deposited in the graves at El-Zuma is fairly consistent (see Volume II, Chapter 6). Based on the pottery evidence, we can attribute El-Zuma to the Transitional Early Ma- 
kuria period. Signs of this transition (from the Terminal Meroitic [AD 550] to the Christian period [AD 6oo]) were first noted in tumulus T. 4 at Hammur-Abbassyia and T.5 at El-Kassinger Bahry (site HP45), and as far north as Sessebi in the Third Nile Cataract region (Mahmoud El-Tayeb 2003; Kołosowska and Mahmoud El-Tayeb 2007, 20-22; Edwards 1994).

Iwona Kozieradzka-Ogunmakin successfully obtained dates from human teeth recovered from three type III tumuli: T.18-AD 83-311; T.21-AD 387-538; and T.24-AD 264-535 (see Chapter 7 , this volume). For various reasons, the mission was not able to carry out $\mathrm{C}_{4} 4$ dating on the available material from the cemetery.

Tumulus 26 (type II) was probably one of the later graves, given that a Dongolan amphora and a bowl with horizontal handles dated to the 7 th century were discovered in the burial chamber. This tumulus was probably built when amphora production was already up and running at Dongola (see Volume II, Chapter 6).

Yet, from the dates cited above, only T. 21 (AD 387-538) and T.26 appear to fit precisely with the dating established from the study of funerary practice and material culture.

Further dating of the cemetery puts El-Zuma in line with other tumulus fields excavated in this middle zone of the Nile Valley, between the Third Nile Cataract and the junction of the two Niles at Khartoum. The nearest parallel to El-Zuma in terms of date is cemetery site HP 45 at El-Kassinger Bahry (see Introduction to this volume).

Given the years of study that have been devoted to various sites in Upper Nubia, remarkably little is known about the political transformation that occurred in the Meroitic centre of power, leading to the disintegration and demise of the kingdom and the subsequent rise of new political entities. Historically, we know that by the mid-4th century AD royal pyramids were no longer used as tombs. Thereafter, several necropolises appeared, characterised by large tumuli, often constructed of earth and gravel or just stones. The spread of these mound burials between Lower Nubia and the Central Nile Valley clearly points to the fact that they were symbols of sovereignty of new local centres of power [Fig. 11.1]. To date, only a few sites of this type have been fully excavated and analysed. The best known are the royal cemeteries at Ballana and Qustul in Lower Nubia, while sites in Upper Nubia, including El-Ghaddar cemeteries South and North, HammurAbbassiya and Tanqasi, still await comprehensive excavation and study. Further upstream are the recently excavated tumuli at Hagar El-Beida in the Abu-Hamed Reach (Chłodnicki and Stępnik 2013). So far El-Hobagi is the bestknown site in the Shendi Reach. A close look at the results obtained from the work carried out at these sites clearly highlights some crucial facts. First, they appear to represent a similar chronological horizon, between the 4th and 6 th centuries AD. They also clearly exhibit signs of an uninterrupted, continuous evolution of Meroitic culture. This continuity in turn provides strong evidence against the erroneous conventional theories on the fall of Meroe having been brought about by foreign invaders. Therefore, as demonstrated by the material remains outlined above, there can be no doubt that the tumuli at El-Zuma are symbols of sovereignty containing burials of local chiefs of the region. However, the exact status of these chiefs cannot be determined until we can devise an appropriate method for excavating the most promising, main burial chambers of T.6 and T.7. As mentioned before, the exploration of these two tumuli was postponed for safety reasons. 


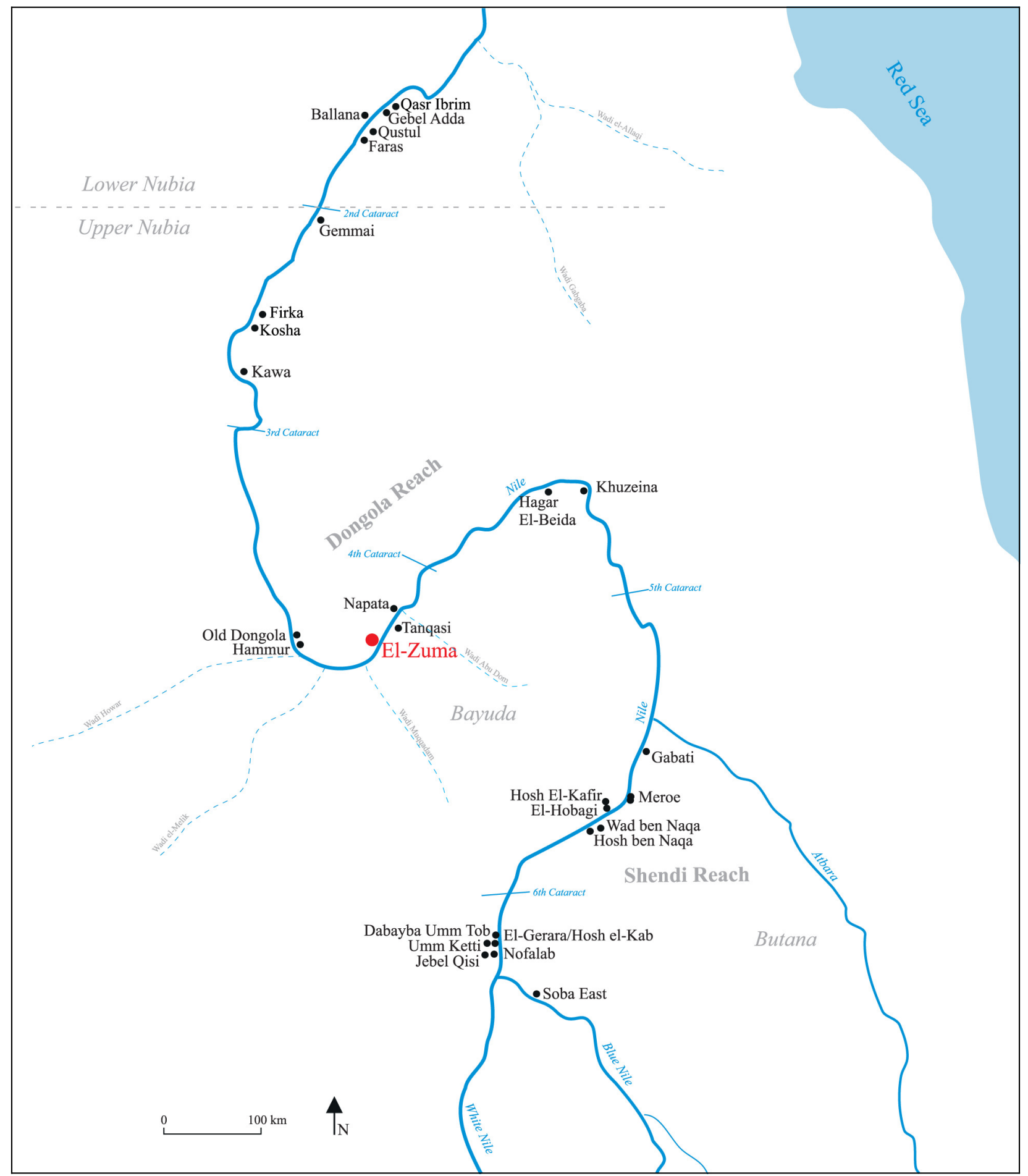

FIGURE 11.1 Map showing sites with post-Meroitic period tumuli DRAWN BY E. CZYŻEWSKA-ZALEWSKA 